\title{
ANÁLISE COMPARATIVA ENTRE OS INDICADORES ECONÔMICO-FINANCEIROS APLICADOS ÀS INDÚSTRIAS MANUFATUREIRAS LISTADAS NA BOVESPA
}

\author{
Luiz Cláudio Louzada ${ }^{1,2}$, Jean Pierre David de Oliveira ${ }^{2}$, Antônio Fernando Pego da Silva ${ }^{2}$ \\ Márcio Augusto Gonçalves ${ }^{1}$ \\ ${ }^{1}$ Universidade Federal de Minas Gerais-CEPEAD/UFMG \\ ${ }^{2}$ Universidade Federal do Espírito Santo-UFES \\ E-mail de contato:louzadalvi@yahoo.com.br
}

\section{RESUMO}

As demonstrações contábeis fornecem informações úteis sobre o patrimônio das unidades empresariais e suas variações e de desempenho, contribuindo para seus mais diversos usuários no processo de tomada de decisão quer seja na dimensão econômica, financeira ou operacional. Neste sentido, percebe-se que a análise relativa é uma das técnicas mais usuais para avaliação do desempenho em setores específicos e, com isso, tem sido fundamentalmente uma técnica comparativa. Porém, acrescenta-se, ainda, que mais importante que calcular um grande número de índices é identificar os indicadores que tenham maior aderência às características das unidades empresariais e dos setores específicos. Neste contexto, o uso de técnicas estatísticas torna-se importante na investigação de índices ou agrupamentos que permitam avaliar setores específicos, contribuindo, assim, para uma melhoria da qualidade das informações no processo de suporte a tomada de decisão referentes à unidade empresarial quando características peculiares de cada um deles são considerados. Diante disso, o objetivo da presente pesquisa foi identificar quais índices econômico-financeiros são mais relevantes para o monitoramento da situação patrimonial no segmento de Indústrias Manufatureiras e, consequentemente, a sua relevância quando aplicados a setores específicos. Para tanto, utilizou-se a técnica de análise fatorial nos indicadores extraídos das demonstrações financeiras, que são fontes de aferição do desempenho econômico-financeiro das empresas. Foram selecionados 24 índices, coletados por meio do banco de dados Economática ${ }^{\circledR}$, das companhias de capital aberto com ações negociadas na Bolsa de Valores, Mercadorias e Futuros (BM\&FBOVESPA) dos setores de indústria manufatureiras, segregadas em siderurgia e metalurgia, alimentos e bebidas, química, têxtil e veículos e peças visando identificar a existência de indicadores comuns e específicos entre os setores e subsetores. Os resultados da análise fatorial mostraram que os índices relevantes para o setor manufatureiro estão agrupados em sete fatores com poder de explicação de $77 \%$ da variabilidade dos dados. A pesquisa mostrou ainda que não há diferenças significativas entre as características de mensuração dos índices do setor de Indústrias Manufatureiras e os seus segmentos específicos.

Palavras-chave:Indicadores econômico-financeiros; Alavancagem operacional; Ciclo operacional; Análise fatorial; Indústria manufatureira. 


\title{
COMPARATIVE ANALYSIS OF THE ECONOMIC AND FINANCIAL INDICATORS APPLIED TO THE MANUFACTURING INDUSTRIES LISTED ON THE BOVESPA
}

\begin{abstract}
The financial statements provide useful information about the equity of the business units and their variations and performance, contributing to their various users in the decision- making process whether in economic, financial or operational dimension. In this sense, it can be noticed that the comparative analysis is one of the most common techniques for assessing performance in specific sectors and, thus, has always been a comparative technique. However, it adds further that more important than calculating a large number of indexes is to identify financial indicators that have greater adherence to the characteristics of business units and specific sectors. In this context, the use of statistical techniques becomes important in the investigation of indices or groups to assess specific sectors, thus contributing to improving the quality of information in support of decision making processes relating to business units when peculiarities of each one of them are considered. Therefore, the aim of this research was to identify which are the most relevant economic and financial indicators for monitoring the financial performance of each of the industries in the manufacturing sector and hence their relevance when applied to specific sectors. For this, we used factor analysis techniques from the indicators extracted from the financial statements, which are our sources of measuring the financial performance of companies. It selected 24 indices, collected through Economática ${ }^{\circledR}$ database, of public companies traded on the Securities, Commodities and Futures Exchange (BM\&FBOVESPA) of manufacturing industry sectors, segregated in steel and metals, food and drinks, chemicals, textiles and motor vehicles aiming to identify the existence of common and specific indicators across sectors and subsectors. The results of the factor analysis showed that the relevant indexes to the manufacturing sector are grouped into seven factors with explanatory power of $77 \%$ of data variation. The research also showed no significant differences between the characteristics of the measurement indexes of manufacturing industries and their specific segments.
\end{abstract}

Keywords: Economic and Financial Indicators; Operating Leverage; Operating Cycle; Factor Analysis; Manufacturing Industry. 


\section{ANÁLISIS COMPARATIVO ENTRE INDICADORES ECONÓMICOS Y FINANCIEROS APLICADOS A LA INDÚSTRIA MANUFACTURERA LISTADOS EN BOVESPA}

\section{RESUMEN}

Los informes contables proporcionan información útil sobre el patrimonio de las unidades de negocio y sus variaciones y el rendimiento, lo que contribuye a sus distintos usuarios en el proceso de toma de decisiones ya sea en la dimensión económica, financiera u operacional. En este sentido, se puede notar que el análisis relativo es una de las técnicas más comunes para la evaluación del desempeño en sectores específicos $\mathrm{y}$, por lo tanto , ha sido esencialmente una técnica comparativa . No obstante, extendiese, también, que lo más importante para el cálculo de un gran número de índices es identificar indicadores que tienen una mayor adherencia a las características de las unidades de negocio y sectores específicos. En este contexto, el uso de técnicas estadísticas se hace importante en la investigación de los índices o grupos para evaluar determinados sectores, contribuyendo así a la mejora de la calidad de la información en apoyo del proceso de toma de decisiones en relación con la unidad de la empresa cuando peculiaridades de cada uno de ellos son considerados. Por lo tanto, el objetivo de esta investigación fue identificar cuáles son los ratios más relevantes para el monitoreo de la situación financiera en el segmento de Industrias Manufactureras y de ahí su importancia cuando se aplica a sectores específicos. Por lo tanto, se utilizó la técnica de análisis de factores de los indicadores extraídos de los informes contables, que son fuentes de medición de los resultados financieros de las empresas. Fueron seleccionados 24 índices, recogidos a través del banco Economática ${ }^{\circledR}$ base de datos de las empresas públicas con acciones negociadas en la Bolsa de Valores, Mercaderías y Futuros (BM \& FBOVESPA) de sectores de la industria manufacturera, segregados en acero y la metalurgia, alimentos y bebidas, productos químicos, textiles y automóviles y piezas para identificar la existencia de indicadores comunes y específicos en todos los sectores y subsectores. Los resultados del análisis factorial mostraron que los índices relevantes para el sector manufacturero se agrupan en siete factores con poder explicativo del $77 \%$ de la variabilidad de los datos. La investigación también mostró diferencias significativas entre las características de los índices de medición del sector de "Industrias manufactureras" y sus segmentos específicos.

Palabras clave: Indicadores Económicos y Financieros; apalancamiento operativo; Ciclo de funcionamiento; análisis factorial; Industria Manufacturera. 


\section{INTRODUÇÃO}

As demonstrações contábeis fornecem informações úteis e compreensíveis a respeito do passado das empresas, o que pode ajudar seus usuários a fazerem previsões e a tomar decisões relativas à situação econômica e financeira futura dos seus negócios. Normalmente, isso é realizado por meio de índices econômico-financeiros calculados a partir de relações entre contas ou grupos de contas das demonstrações contábeis das empresas (CORRAR; PAULO; DIAS FILHO, 2007, p.11).

Um dos objetivos da análise de desempenho das empresas é relacionar índices para avaliar o desempenho de uma empresa no seu mercado. Entretanto, Assaf Neto (2008, p.63), ressalta que a análise das demonstrações é fundamentalmente comparativa, isto é, um determinado índice, se avaliado isoladamente não contém informação necessária para uma conclusão, logo, é de extrema importância que se conheça como evoluiu esse indicador nos últimos anos e em que nível ele se situa em relação aos concorrentes e aos padrões de mercado. Além disso, Matarazzo (1998, p.154) afirma que "o importante não é o cálculo de um grande número de índices, mas de um conjunto de índices que permitam conhecer a situação da empresa, segundo o grau de profundidade desejada da análise.”

Nessa perspectiva, ao longo do tempo diversos pesquisadores têm contribuído com modelos que se utilizam de técnicas estatísticas para avaliar a situação econômico-financeira das empresas. Segundo Silva (2008, p.10), destaca-se entre eles Edward Altman que utilizou técnicas de análise discriminante múltipla para prever a insolvência de empresas. Nesse sentido, Kassai (2002), cita Stephen Kanitz que com seus estudos foi responsável pela publicação "Melhores e Maiores", da revista Exame, e mais tarde originou o livro "Como prever falências", publicado em 1978.

Note-se, portanto, que o uso de técnicas estatísticas torna-se importante na construção de um conjunto de índices que permitam avaliar o desempenho econômico-financeiro e operacional de uma empresa em relação ao mercado, contribuindo, assim, para uma melhoria da qualidade das informações que poderão auxiliar a tomada de decisões dos administradores das empresas.

Hair (2009, p.23) comenta que,

[..] a informação disponível na tomada de decisões explodiu nos últimos anos e irá continuar assim no futuro [...] muita dessa informação simplesmente desaparecia, ou não era coletada, ou era descartada, hoje, essa informação está sendo coletada e armazenada em bancos de dados e está disponível para ser feita a "garimpagem" para fins de melhoria na tomada de decisões [...] parte dessa 
informação pode ser analisada e compreendida com estatísticas simples, mas uma grande porção demanda técnicas estatísticas multivariadas mais complexas para transformar os dados em informações mais completas [...] as técnicas de análise multivariadas são populares porque elas permitem que empresas criem conhecimentos, melhorando assim suas tomadas de decisões (grifo nosso).

Desta forma, a presente pesquisa buscou responder a seguinte questão problema: Quais índices são relevantes para a análise econômico-financeira das empresas do setor de Indústria Manufatureira e os segmentos?

A pesquisa teve por objetivo identificar, por meio da utilização da técnica de análise fatorial, os índices de maior importância para o setor de Indústrias Manufatureiras. A pesquisa permitiu ainda, verificar a relevância e o padrão dos índices do setor Manufatureiro e seus segmentos, com o intuído de identificar se existem relações entre os indicadores e os setores analisados.

Ante o exposto, com as informações produzidas na análise das demonstrações financeiras e com a utilização de técnicas estatísticas de análise multivariada, desenvolveu-se o processo de análise que foi utilizado na presente pesquisa, o qual é apresentado na Figura 1.

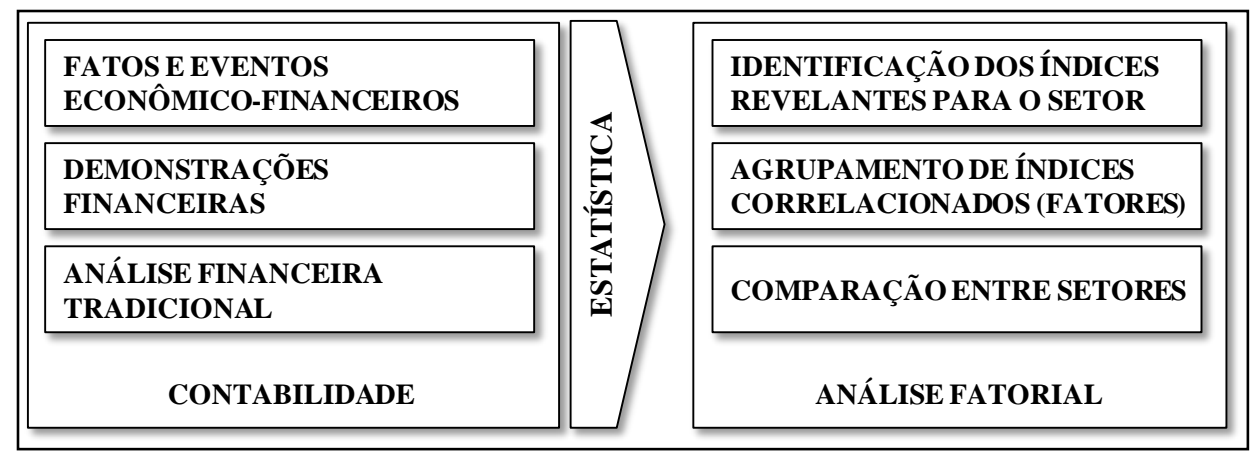

Figura 1: Processo de análise utilizado na pesquisa

Fonte: Elaborado pelos autores

A pesquisa se justifica em termos teóricos por se constituir em uma das tentativas de aliar as técnicas estatísticas de análise multivariada à análise das demonstrações financeiras. A pesquisa justifica-se ainda, em termos práticos, na medida em que propõe uma metodologia que permite aos tomadores de decisão identificar os índices mais relevantes para o seu segmento de mercado, identificar a importância de cada um deles para o processo de tomada de decisão e ainda identificar se existe um agrupamento de índices que possa gerar as informações que necessitam para analisar a situação de uma empresa em setores específicos.

\section{ANÁLISE MULTIVARIADA E ANÁLISE FATORIAL}

A análise multivariada refere-se a todas as técnicas estatísticas que simultaneamente analisam múltiplas medidas sobre indivíduos ou objetos sob investigação. Assim, qualquer 
análise simultânea de mais de duas variáveis pode ser considerada, em princípio, como multivariada. Porém, para serem consideradas multivariadas, todas as variáveis devem ser aleatórias e inter-relacionadas de tal maneira que seus diferentes efeitos não podem ser significativamente interpretados em separado. No entanto, alguns autores estabelecem que o objetivo da análise multivariada seja medir, explicar e prever o grau de relação entre variáveis estatísticas. Desta forma, o caráter multivariado reside nas múltiplas variáveis estatísticas (combinações múltiplas de variáveis), e não somente no número de variáveis ou observações (HAIR, 2009, p.23).

Das várias técnicas multivariadas, Hair (2009, p.23) descreve que a análise fatorial, que inclui análise de componentes principais e análise dos fatores comuns, é uma abordagem estatística que pode ser útil para se analisar inter-relações entre um grande número de variáveis e explicar essas variáveis em termos de suas dimensões inerentes comuns (fatores). Sendo assim, o objetivo é encontrar um meio de condensar a informação contida em várias variáveis originais em um conjunto menor de variáveis estatísticas (fatores) com uma perda mínima de informação. Análise fatorial é uma técnica de interdependência, cujo propósito principal é definir a estrutura inerente entre as variáveis da análise.

Hair (2009, p.102) destaca que,

[...] à medida que acrescentamos mais e mais variáveis, cada vez mais a sobreposição (ou seja, correlação) acontece entre as mesmas [...] quando as variáveis se tornam correlacionadas, o pesquisador precisa de caminhos para gerenciar essas variáveis, agrupando variáveis altamente correlacionadas, rotulando ou nomeando os grupos [...] a análise fatorial fornece as ferramentas para analisar a estrutura das inter-relações (correlações) em um grande número de variáveis definindo conjuntos de variáveis que são fortemente inter-relacionadas, conhecidos como fatores [...] esses fatores são por definição altamente inter-correlacionados, são considerados como representantes de dimensões dentro dos dados.

Segundo Mingoti (2007, p.99) a análise fatorial tem com objetivo descrever a variabilidade original do vetor aleatório $X$, em termos de um número menor de $m$ variáveis aleatórias, chamadas de fatores comuns e que estão relacionadas com o vetor original $X$ através de um modelo linear. Neste modelo, parte da variabilidade de $X$ é atribuída aos fatores comuns, sendo o restante da variabilidade de $X$, atribuída às variáveis que não foram incluídas no modelo, ou seja, ao erro aleatório.

No processo de decisão em análise fatorial, Hair (2009, p.104) sugere sete estágios, o ponto de partida em análise fatorial, bem como em outras técnicas estatísticas, é o problema de pesquisa, assim ao atingir seus objetivos, a análise fatorial é ajustada tendo em vista quatro questões: especificação da unidade de análise; obtenção do resumo de dados e/ou redução dos 
mesmos; seleção de variáveis e uso de resultados da análise fatorial com outras técnicas multivariadas.

\section{BASE DE DADOS E ESTRATÉGIA DE PESQUISA}

A amostra desta pesquisa foi extraída do banco de dados Economática ${ }^{\circledR}$, empresa especializada em informações para o mercado de capitais. Os dados analisados referem-se a todas as empresas com ações comercializadas na Bolsa de Valores de São Paulo (BOVESPA), no período de 2004 a 2008. A amostra das empresas é composta por 388 empresas em 2004, 383 em 2005, 412 em 2006, 414 em 2007 e 391 em 2008.

A classificação e o tipo de mercado de cada empresa foram retirados do banco de dados Economática ${ }^{\circledR}$, seguindo o critério do primeiro nível do NAICS (North American Industrial Classification). Segundo Borschiver, Wongtschowki; Antunes (2004, p.11), a NAICS levou também em consideração as necessidades estatísticas da ALCA (Acordo de Livre Comércio das Américas), assinado em janeiro de 1994, que previa o desenvolvimento da classificação industrial comum a todos os países pertencentes a ALCA.

Foram selecionadas todas as empresas disponíveis nos anos de 2004 a 2008 e constatou-se que algumas empresas não possuíam informações de todas as variáveis; assim foi necessário tratar os dados perdidos. O tratamento dessas informações "perdidas" se deu por meio dos recursos disponíveis no software SPSS 15.0, que exclui os casos que têm valores perdidos para qualquer das variáveis usadas em qualquer uma das análises. Os cálculos, a elaboração de tabelas e gráficos, foram desenvolvidos por meio dos softwares SPSS 15.0 e Microsoft Excel 2007.

Desta forma, foi possível incluir um maior número de empresas nas análises, permitindo posteriormente realizar análises em um nível mais detalhado nos segmentos de mercado selecionados do setor de Indústria Manufatureira. O estudo se limitou a avaliar o padrão dos índices do setor de Indústria Manufatureira, tendo em vista o grande número de empresas deste setor que foi observado em todo o período estudado (Ver Tabela 6 na Seção 4).

Desta forma, realizou-se inicialmente uma análise fatorial nos anos selecionados a fim de reduzir as variáveis que visam sintetizar informações por meio dos fatores comuns, que expliquem parte da variabilidade total dos dados originais. Em seguida, utilizaram-se as variáveis extraídas para realizar a análise no setor de Indústria Manufatureira, com o mesmo intuído descrito anteriormente. Por fim, foram analisadas e comparadas as variáveis extraídas por meio dos fatores comuns do setor de Indústria Manufatureira com os segmentos de 
"Siderurgia e Metalurgia"; "Alimentos e Bebidas"; "Química"; "Têxtil” e "Veículos e Peças". Estes segmentos do setor de Indústria Manufatureira foram selecionados por possuírem o maior número de empresas disponível na amostra (Ver Tabela 6 na Seção 4). A Figura 2 ilustra a aplicação da análise fatorial (AF) nos dados que compuseram a amostra da pesquisa.

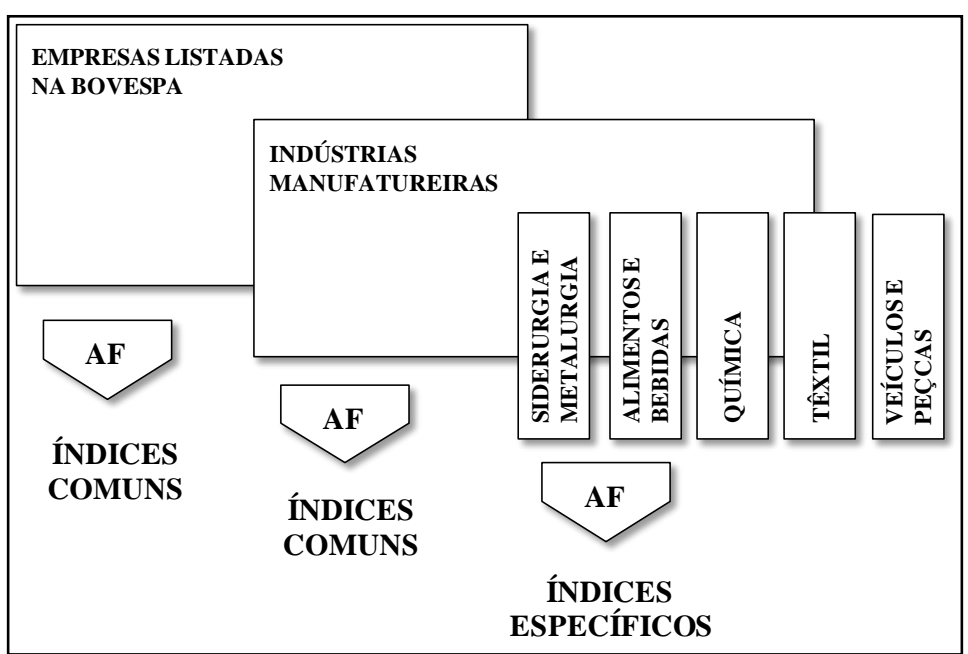

Figura 2: Aplicação da análise fatorial na amostra Fonte: Elaborado pelos autores

Foram selecionados 24 índices a fim de determinar os mais relevantes. Todos os índices foram extraídos do banco de dados Economática ${ }^{\circledR}$ sem a necessidade de cálculo posterior. A Tabela 1 apresenta os índices selecionados e os códigos utilizados para identificação dos mesmos. Estes índices foram selecionados a partir de uma revisão da literatura relacionada com a análise das demonstrações financeiras. Dentre os autores consultados destacam-se: Gitman (1997), Ross; Westerfield; Jaffe (2002), Brigham; Gapenski; Ehrhardt (2001), Bodie e Merton (1999), Assaf Neto (2008), Matarazzo (1998), Silva (2008).

Tabela 1: Índices selecionados e códigos utilizados

\begin{tabular}{|c|c|c|}
\hline Variáveis & Índices & Códigos \\
\hline 1 & Margem Líquida & ML \\
\hline 2 & Liquidez Corrente & $\mathrm{LC}$ \\
\hline 3 & Participação de Capital de Terceiros & $\mathrm{CT}$ \\
\hline 4 & Imobilização do Patrimônio Liquido & IPL \\
\hline 5 & Liquidez Geral & LG \\
\hline 6 & Liquidez Seca & LS \\
\hline 7 & Rentabilidade do Ativo & ROA \\
\hline 8 & Giro do Ativo & GA \\
\hline 9 & Percentual da Dívidas de Curto Prazo sobre o Endividamento Geral & DCP \\
\hline 10 & Margem Operacional & MO \\
\hline 11 & Margem Bruta & MB \\
\hline 12 & Rentabilidade do Patrimônio Liquido & ROE \\
\hline
\end{tabular}




\begin{tabular}{clc} 
Universidade do Estado de Santa Catarina \\
Centro de Educação Superior do Alto Vale do Itajaí \\
13 & Margem EBITDA & ME \\
14 & Prazo Médio de Estocagem & PME \\
15 & Prazo Médio de Recebimento & PMR \\
16 & Prazo Médio de Fornecedor & PMF \\
17 & Grau de Alavancagem Financeira & GAF \\
18 & Grau de Alavancagem Operacional & GAO \\
19 & Valor do Lucro por Ação & VLPA \\
20 & Valor Patrimonial por Ação & VPA \\
21 & Vendas por Ação & VA \\
22 & Imobilização de recursos Não Correntes & IRNC \\
23 & Ciclo Financeiro & CFin \\
24 & Ciclo Operacional & Cope \\
\hline \hline
\end{tabular}

Fonte: Elaborado pelos autores com base na revisão de literatura

\section{ANÁLISE E TRATAMENTO DOS DADOS}

Algumas suposições devem ser verificadas para validar o uso da análise fatorial. Para isso são avaliados os testes de Kaiser-Meyer-Olkin (KMO), esfericidade de Bartlett's e as comulalidades das variáveis em cada período da amostra selecionada.

$\mathrm{O}$ teste KMO e o teste de Bartlett's de Esfericidade indicam a adequação dos dados à análise fatorial. O KMO é um teste estatístico que indica a proporção da variância dos dados que pode ser considerada comum a todas as variáveis, ou seja, que pode ser atribuída a um fator comum. $\mathrm{O}$ valor de $\mathrm{KMO}$ varia de 0 a 1 e estabelece como adequado quando seu valor está próximo de 1 e pelo menos maior do que 0,5. Para Hair (2009, p.110), o teste de Bartlett's é um outro modo de determinar a adequação da análise fatorial examinando a matriz de correlação inteira. É um teste estatístico para a presença de correlação entre as variáveis. Ele verifica se a matriz de correlação é uma matriz identidade, caso seja, não há correlação entre as variáveis. Então, a um determinado nível de significância estatística (neste estudo considerou $5 \%$, ou seja, $\alpha=0,05$ ), busca-se rejeitar a hipótese nula para considerar o modelo fatorial como sendo adequado.

Na Tabela 2, pode-se observar que os valores de KMO foram maiores que 0,5 e o teste de Bartlett's obteve um p-valor menor que 0,05 em todo o período selecionado. Portando, os dados foram considerados adequados para o objetivo de análise fatorial.

Tabela 2: Resultado do teste de KMO e esfericidade de Bartlett's

\begin{tabular}{llllll}
\hline \hline & 2004 & 2005 & 2006 & 2007 & 2008 \\
\hline
\end{tabular}


Kaiser-Meyer-Olkin Medida de Adequação de Amostragem

$$
0,634 \quad 0,635 \quad 0,605 \quad 0,556 \quad 0,573
$$

\begin{tabular}{lcccccc}
\hline \multirow{2}{*}{$\begin{array}{l}\text { Teste de } \\
\text { Esfericidade de }\end{array}$} & Aprox. Qui-Quadrado & $7.175,60$ & $6.741,71$ & $6.926,84$ & $6.910,20$ & $4.590,78$ \\
Bartlett's & DF & 276 & 276 & 276 & 276 & 276 \\
\cline { 2 - 6 } & Sig. & 0,0000 & 0,0000 & 0,0000 & 0,0000 & 0,0000 \\
\hline \hline
\end{tabular}

Fonte: Elaborado pelos autores.

Quando uma variável é correlacionada com outra, costuma-se dizer que ela compartilha variância com a outra variável. Essa quantia de variância partilhada entre duas variáveis é simplesmente a correlação ao quadrado. Por exemplo, se duas variáveis têm uma correlação de 0,50 , cada variável compartilha com $25 \%(0,50)^{2}$ de sua variância com a outra. Em análise fatorial, agrupam-se variáveis por suas correlações, de modo que variáveis em um grupo (fator) têm elevadas correlações umas com as outras.

Desta forma, para propósitos de análise fatorial, é importante entender o quanto da variância de uma variável é compartilhado com outras variáveis. A variância comum é definida como aquela variância em uma variável que é compartilhada com todas as outras variáveis na análise. Essa variância é explicada (compartilhada) com base nas correlações de uma variável com as demais na análise. A comunalidade de uma variável é a estimativa de sua variância compartilhada, ou em comum, entre as variáveis como representadas pelos fatores obtidos (HAIR, 2009, p.112).

A Tabela 3 permite analisar as comunalidades das variáveis e verificar que os índices: Ciclo Operacional (COpe) e Liquidez Corrente (LC) apresentam altos valores em todos os anos e devem acrescentar um maior grau de informação para o sistema; já o Grau de Alavancam Operacional (GAO), Prazos Médio de Fornecedor (PMF) e Imobilização dos Recursos Não Corrente (IRNC), apresentam valores baixos em alguns dos anos analisados e devem fornecer um baixo grau de informação para o sistema.

Tabela 3: Comunalidades dos indicadores ano a ano

\begin{tabular}{cccccc}
\hline \hline \multirow{2}{*}{ Índices } & \multicolumn{5}{c}{ Extração } \\
\cline { 2 - 6 } & $\mathbf{2 0 0 4}$ & $\mathbf{2 0 0 5}$ & $\mathbf{2 0 0 6}$ & $\mathbf{2 0 0 7}$ & $\mathbf{2 0 0 8}$ \\
\hline COpe & 0,981 & 0,978 & 0,960 & 0,990 & 0,958 \\
LC & 0,915 & 0,902 & 0,942 & 0,902 & 0,926 \\
CFin & 0,958 & 0,828 & 0,910 & 0,945 & 0,935 \\
LS & 0,890 & 0,830 & 0,909 & 0,913 & 0,921 \\
MO & 0,849 & 0,818 & 0,853 & 0,958 & 0,865 \\
ML & 0,829 & 0,855 & 0,813 & 0,955 & 0,836 \\
VPA & 0,845 & 0,908 & 0,862 & 0,848 & 0,783 \\
ROA & 0,800 & 0,887 & 0,880 & 0,847 & 0,810 \\
VA & 0,777 & 0,858 & 0,881 & 0,860 & 0,803 \\
PME & 0,793 & 0,778 & 0,866 & 0,903 & 0,741
\end{tabular}




\begin{tabular}{cccccc} 
LG & 0,815 & 0,773 & 0,789 & 0,794 & 0,828 \\
VLPA & 0,764 & 0,846 & 0,660 & 0,871 & 0,768 \\
ME & 0,775 & 0,820 & 0,726 & 0,902 & 0,608 \\
ROE & 0,654 & 0,686 & 0,725 & 0,829 & 0,762 \\
GAF & 0,809 & 0,851 & 0,582 & 0,773 & 0,612 \\
CT & 0,736 & 0,690 & 0,696 & 0,758 & 0,631 \\
GA & 0,638 & 0,605 & 0,724 & 0,758 & 0,703 \\
MB & 0,717 & 0,661 & 0,673 & 0,723 & 0,642 \\
IPL & 0,548 & 0,642 & 0,565 & 0,794 & 0,667 \\
GAO & 0,873 & 0,782 & 0,466 & 0,537 & 0,526 \\
DCP & 0,686 & 0,582 & 0,597 & 0,609 & 0,688 \\
PMR & 0,655 & 0,589 & 0,608 & 0,640 & 0,659 \\
PMF & 0,659 & 0,599 & 0,753 & 0,648 & 0,456 \\
IRNC & 0,397 & 0,745 & 0,350 & 0,657 & 0,393 \\
\hline \hline
\end{tabular}

Universidade do Estado de Santa Catarina

Centro de Educação Superior do Alto Vale do Itajaí

Fonte: Elaborado pelos autores.

Nesta pesquisa, optou-se por excluir as variáveis que apresentam uma comunalidade abaixo de 0,5. Como estas variáveis não acrescentam muitas informações para análise fatorial, é possível com isto, aumentar o grau de adequação dos dados nos anos em que as variáveis foram excluídas. Portanto, para o ano de 2004 foi excluída a variável IRNC, em 2006 foram excluídos GAO e IRNC e em 2008 as variáveis PMF e IRNC. Após a exclusão das variáveis, foi realizada uma nova verificação de adequação dos dados à análise fatorial. Os novos resultados podem ser observados na Tabela 4.

Tabela 4: Teste de KMO e esfericidade (Bartlett's) após exclusão das variáveis com baixa comunalidade

\begin{tabular}{llrrrrr}
\hline \hline & $\mathbf{2 0 0 4}$ & $\mathbf{2 0 0 5}$ & $\mathbf{2 0 0 6}$ & $\mathbf{2 0 0 7}$ & $\mathbf{2 0 0 8}$ \\
\hline $\begin{array}{l}\text { Kaiser-Meyer-Olkin Medida de Adequação } \\
\text { de Amostragem }\end{array}$ & 0,639 & 0,635 & 0,615 & 0,556 & 0,632 \\
\hline $\begin{array}{l}\text { Teste de } \\
\begin{array}{l}\text { Esfericidade de } \\
\text { Bartlett's }\end{array}\end{array}$ & Aprox. Qui-Quadrado & $7.693,74$ & $6.741,71$ & $7.490,62$ & $6.910,20$ & $3.047,94$ \\
\cline { 2 - 7 } & Sig. & 253 & 276 & 231 & 276 & 231 \\
\hline \hline
\end{tabular}

Fonte: Elaborado pelos autores.

De acordo com o teste KMO, houve uma melhora na adequação dos dados à análise fatorial nos anos onde ocorreram exclusões das variáveis com baixas comunalidades. Assim, como anteriormente, todo o período selecionado foi considerado adequado a utilização da análise fatorial.

Como os anos de 2004 e 2005 apresentaram os maiores valores de KMO, 0,639 e 0,635, respectivamente, as análises para o mercado de Indústria Manufatureira foram realizadas com base neste período. Embora o ano de 2008 também pudesse ser incluído na análise, optou-se por desconsiderá-lo, tendo em vista a crise econômica mundial iniciada em 


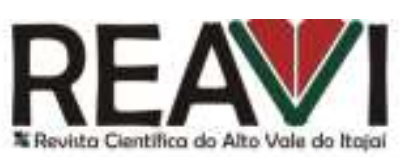

Universidade do Estado de Santa Catarina

Centro de Educação Superior do Alto Vale do Itajaí

setembro daquele ano, a qual pode ter provocado distorções nos indicadores econômicofinanceiros.

Segundo Hair (2009, p.115), na prática, a maioria dos pesquisadores raramente usam um único critério para determinar quantos fatores devem ser extraídos. Desta forma, sugere selecionar um número de fatores suficientes para atender um percentual especificado de variância explicada, geralmente $60 \%$ ou mais, e o teste do "Scree Plot" fazendo o gráfico da raiz latente (autovalores) em relação ao número de componentes (fatores) em sua ordem de extração, e a forma da curva resultante é usada para avaliar o ponto de corte.

Levando-se em consideração o objetivo desta pesquisa que é o de reduzir e identificar os índices mais relevantes, optou-se por utilizar na identificação dos índices um valor da carga fatorial maior ou igual a $+0,7$, ou menor ou igual -0,7. Segundo Hair (2009, p.119), carga fatorial é a correlação da variável e do fator; e a carga ao quadrado é a quantia de variância total da variável e do fator. Assim, uma carga de $\pm 0,30$ reflete aproximadamente $10 \%$ de explicação, e uma carga de $\pm 0,50$ denota que $25 \%$ da variância é explicada pelo fator. A carga deve exceder $\pm 0,70$ para que o fator explique $50 \%$ da variância de uma variável. Logo, quanto maior o módulo do valor absoluto da carga fatorial, mais importante a carga na interpretação da matriz fatorial. Assim, após as análises da matriz dos componentes rotacionada e do "Scree Plot" nos anos selecionados, foram extraídos sete grupos fatores, conforme demonstrado na Tabela 5.

Os índices que compõem os fatores extraídos são muito próximos, com exceção de cinco variáveis: o índice "Capital de Terceiros" no Fator 3 de 2004, que não foi incluído no modelo de 2005 em nenhum fator; e o mesmo acontece com o "Giro do Ativo" no Fator 5 de 2004 e o "Grau de Alavancagem Operacional" no Fator 6; já o Fator 7 apresenta divergência em ambos os anos, em 2004 o modelo considerou o "Percentual da Dívida de Curto Prazo sobre o Endividamento Geral" e para 2005 foi incluído o índice "Imobilização dos Recursos não Correntes". Segundo Assaf Neto (2008, p.249), estes indicadores são utilizados, basicamente, para aferir a composição (estrutura) das fontes passivas de recursos de uma empresa e mostram a forma como os recursos de terceiros são utilizados pela empresa e qual a sua participação relativa em relação ao capital próprio. Assim, apesar das aparentes divergências, ambos medem a estrutura de capital da empresa.

O período analisado apresentou também 17 índices em comum: "Margem Líquida", "Margem Operacional", "Rentabilidade do Ativo" e "Rentabilidade do Patrimônio Líquido" no Fator 1; estes índices avaliam a situação econômica da empresa, indicando qual retorno 
que a empresa pode ter pelo seu empreendimento, assim pode-se denominar o Fator $1 \mathrm{de}$ Fator de Rentabilidade. O Fator 2 tem em comum o "Ciclo Financeiro", "Ciclo Operacional", "Prazos Médio de Estocagem" e "Prazo Médio de Recebimento"; índices que representam o ciclo operacional da empresa com relação à movimentação de recebimento e entrega de mercadorias, então se denominou como Fator de Ciclo Operacional.

Para o Fator 3, os índices de liquidez, os quais demonstram a base da situação financeira das empresas, mostram-se absolutos, estando presentes tanto no ano de 2004 quanto no ano de 2005; entretanto, no ano de 2004 uma variável associada à estrutura de capital das empresas mostrou-se presente, o "Capital de Terceiros", desta forma denominouse este fator de Fator de Liquidez e Estrutura de Capital. Indicadores de "Valor Patrimonial por Ação", "Valor do Lucro por Ação" e "Vendas por Ação" visam medir o desempenho econômico das empresas, por isso o Fator 4 foi denominado de Fator de Desempenho Econômico.

Tabela 5: Comparação dos fatores extraídos para todas as empresas nos anos de 2004 e 2005

\begin{tabular}{|c|c|c|c|c|}
\hline \multirow{3}{*}{ Fatores } & \multicolumn{4}{|c|}{ Ano } \\
\hline & \multicolumn{2}{|l|}{2004} & \multicolumn{2}{|l|}{2005} \\
\hline & Índice & $\begin{array}{l}\text { \% Variância } \\
\text { Total }\end{array}$ & Índice & $\begin{array}{c}\text { \% Variância } \\
\text { Total }\end{array}$ \\
\hline Fator 1 & $\begin{array}{l}\text { - Margem Líquida } \\
\text { - Margem Operacional } \\
\text { - Rentabilidade do Ativo } \\
\text { - Rentabilidade do Patrimônio } \\
\text { Líquido }\end{array}$ & 16,14 & $\begin{array}{l}\text { - Margem Líquida } \\
\text { - Margem Operacional } \\
\text { - Rentabilidade do Ativo } \\
\text { - Rentabilidade do Patrimônio } \\
\text { Líquido }\end{array}$ & 15,85 \\
\hline Fator 2 & $\begin{array}{l}\text { - Ciclo Financeiro } \\
\text { - Ciclo Operacional } \\
\text { - Prazo Médio de Estocagem } \\
\text { - Prazo Médio de Recebimento }\end{array}$ & 14,72 & $\begin{array}{l}\text { - Ciclo Financeiro } \\
\text { - Ciclo Operacional } \\
\text { - Prazo Médio de Estocagem } \\
\text { - Prazo Médio de Recebimento }\end{array}$ & 14,71 \\
\hline Fator 3 & $\begin{array}{l}\text { - Capital de Terceiros } \\
\text { - Liquidez Corrente } \\
\text { - Liquidez Geral } \\
\text { - Liquidez Seca }\end{array}$ & 14,55 & $\begin{array}{l}\text { - Liquidez Corrente } \\
\text { - Liquidez Geral } \\
\text { - Liquidez Seca }\end{array}$ & 14,25 \\
\hline Fator 4 & $\begin{array}{l}\text { - Valor Patrimonial por Ação } \\
\text { - Valor do Lucro por Ação } \\
\text { - Vendas da Ação }\end{array}$ & 10,16 & $\begin{array}{l}\text { - Valor Patrimonial por Ação } \\
\text { - Valor do Lucro por Ação } \\
\text { - Vendas da Ação }\end{array}$ & 10,56 \\
\hline Fator 5 & $\begin{array}{l}\text { - Margem Bruta } \\
\text { - Giro do Ativo }\end{array}$ & 9,82 & - Margem Bruta & 8,98 \\
\hline Fator 6 & $\begin{array}{l}\text { - Grau de Alavancagem Financeira } \\
\text { - Grau de Alavancagem } \\
\text { Operacional }\end{array}$ & 8,25 & $\begin{array}{l}\text { - Grau de Alavancagem Financeira } \\
\text { - Grau de Alavancagem } \\
\text { Operacional }\end{array}$ & 7,58 \\
\hline Fator 7 & $\begin{array}{l}\text { - \% Dívida de Curto Prazo Sobre o } \\
\text { Endividamento Geral }\end{array}$ & 5,70 & $\begin{array}{l}\text { - Imobilização dos Recursos Não } \\
\text { Correntes }\end{array}$ & 5,20 \\
\hline
\end{tabular}

Fonte: Elaborado pelos autores. 
Igualmente aos índices que compõem o Fator 1 a "Margem Bruta" e o "Giro do Ativo" medem a rentabilidade da empresa, assim, o Fator 5 também é um Fator de Rentabilidade. $\mathrm{O}$ Fator 6 dos dois anos é composto pelo "Grau de Alavancagem Financeira” e o "Grau de Alavancagem Operacional", assim, denominou o referido fator com o Fator de Alavancagem. Como descrito anteriormente, apesar da aparente divergência o Fator 7 apresenta índices de estrutura de capital, logo foi denominado de Fator de Estrutura de Capital.

Em síntese, dos 24 índices apresentados na Tabela 2, entre as empresas com ações comercializadas na BOVESPA no ano de 2004, 20 índices foram considerados relevantes com poder de explicação de 79,34\% da variação total dos dados, agrupados em sete fatores. Para o ano de 2005, 18 índices foram relevantes com poder de explicação de 77,13\%, também agrupados em sete fatores. Cabe destacar que, dos 24 índices, 17 aparecem tanto no exercício de 2004 quanto no exercício de 2005.

Após a análise fatorial da amostra de todas as empresas comercializadas na BOVESPA, selecionou-se apenas o mercado de Indústrias Manufatureiras, de acordo com o primeiro nível do NAICS, com a finalidade de verificar se os índices extraídos nos anos de 2004 e 2005 são os relevantes para este mercado. Desta forma, foi realizada uma nova análise fatorial dentro do mercado de Indústria Manufatureira, com o intuído de analisar alguns dos seus segmentos, quais sejam: "Siderurgia e Metalurgia", "Alimentos e Bebidas", "Química”, "Têxtil" e "Veículos e Peças".

$\mathrm{Na}$ Tabela 6 pode ser observado o número de empresas que compunham o setor de Indústria Manufatureira e os respectivos segmentos selecionados para compor a amostra que foi analisada.

Tabela 6 - Número de empresas por setor

\begin{tabular}{lcc}
\hline \hline Setor/Segmento & $\mathbf{2 0 0 4}$ & $\mathbf{2 0 0 5}$ \\
\hline Indústria Manufatureiras & 170 & 163 \\
Siderurgia e Metalurgia & 34 & 32 \\
Alimentos e Bebidas & 25 & 21 \\
Química & 22 & 19 \\
Têxtil & 29 & 29 \\
Veículos e Peças & 19 & 19 \\
\hline Fonte: Elaborado pelos autores.
\end{tabular}

A Tabela 7 permite observar, que para o setor de Indústrias Manufatureiras, tem-se uma redução de 20 para 16 índices em 2004 e de 18 para 16 índices em 2005; observa-se ainda que alguns fatores fossem compostos com o mesmo conjunto de variáveis em relação à amostra total. Por exemplo, neste mercado pode-se denominar o Fator 1 nos dois anos como Fator de Ciclo Operacional, assim como o Fator 2 da análise da amostra total. Observou-se 
essa particularidade nos dois anos: em 2004 o Fator 3 como Fator de Liquidez e Estrutura de Capital e em 2005 os Fatores 4 e 5, denominados, respectivamente, como Fator de Desempenho Econômico e Fator de Alavancagem.

No setor de Indústria Manufatureira, para o período estudado, tem-se os seguintes índices em comum: "Ciclo Financeiro", "Ciclo Operacional", "Grau de Alavancagem Financeira”, "Grau de Alavancagem Operacional", "Liquidez Corrente”, "Liquidez Geral”, “Liquidez Seca”, "Margem Líquida”, "Margem Operacional”, "Prazo Médio de Estocagem”, "Prazo Médio de Recebimento", "Rentabilidade do Ativo" e "Valor Patrimonial por Ação". A Figura 3 ilustra os índices em comum e os índices específicos entre os anos.

Portanto, com as variáveis relevantes selecionadas para cada ano no setor de Indústria Manufatureira, verificou-se o padrão e o comportamento destas variáveis para os segmentos selecionados do setor manufatureiro.

Tabela 7 - Comparação dos fatores extraídos do setor de indústria manufatureira nos anos de 2004 e 2005

\begin{tabular}{|c|c|c|c|c|}
\hline \multirow{3}{*}{ Fatores } & \multicolumn{4}{|c|}{ Ano } \\
\hline & 2004 & & 2005 & \\
\hline & Índices & $\begin{array}{c}\text { \% Variância } \\
\text { Total }\end{array}$ & Índices & $\begin{array}{c}\text { \% Variância } \\
\text { Total }\end{array}$ \\
\hline Fator 1 & $\begin{array}{l}\text { - Ciclo Financeiro } \\
\text { - Ciclo Operacional } \\
\text { - Prazo Médio de Estocagem } \\
\text { - Prazo Médio de Recebimento }\end{array}$ & 17,88 & $\begin{array}{l}\text { - Ciclo Financeiro } \\
\text { - Ciclo Operacional } \\
\text { - Prazo Médio de Estocagem } \\
\text { - Prazo Médio de Recebimento }\end{array}$ & 18,76 \\
\hline Fator 2 & $\begin{array}{l}\text { - Capital de Terceiros } \\
\text { - Liquidez Corrente } \\
\text { - Liquidez Geral } \\
\text { - Liquidez Seca }\end{array}$ & 15,25 & $\begin{array}{l}\text { - Margem Liquida } \\
\text { - Margem Operacional } \\
\text { - Rentabilidade do Ativo }\end{array}$ & 18,00 \\
\hline Fator 3 & $\begin{array}{l}\text { - Margem Liquida } \\
\text { - Margem Operacional } \\
\text { - \% Dívida de Curto Prazo Sobre o } \\
\text { Endividamento Geral }\end{array}$ & 14,71 & $\begin{array}{l}\text { - Liquidez Corrente } \\
\text { - Liquidez Geral } \\
\text { - Liquidez Seca }\end{array}$ & 16,29 \\
\hline Fator 4 & $\begin{array}{l}\text { - Rentabilidade do Ativo } \\
\text { - Rentabilidade do Patrimônio } \\
\text { Liquido } \\
\text { - Grau de Alavancagem Financeira }\end{array}$ & 13,46 & $\begin{array}{l}\text { - Valor Patrimonial por Ação } \\
\text { - Valor do Lucro por Ação } \\
\text { - Vendas da Ação }\end{array}$ & 14,55 \\
\hline Fator 5 & - Valor Patrimonial por Ação & 11,68 & $\begin{array}{l}\text { - Grau de Alavancagem Financeira } \\
\text { - Grau de Alavancagem } \\
\text { Operacional }\end{array}$ & 9,81 \\
\hline Fator 6 & $\begin{array}{l}\text { - Grau de Alavancagem } \\
\text { Operacional }\end{array}$ & 6,06 & $\begin{array}{l}\text { - Imobilização dos Recursos Não } \\
\text { Correntes }\end{array}$ & 6,35 \\
\hline
\end{tabular}

Fonte: Elaborado pelos autores.

Uma nova da análise sobre os cinco segmentos selecionados do setor de Indústrias Manufatureiras permitiu identificar que a variância explicada foi acima de $80 \%$ em todos os segmentos no período estudado, sendo que o segmento de "Veículos e Peças" obteve a maior 
variância explicada com 96,21\% em 2004 e 90,97\% em 2005 e o segmento de "Siderurgia e Metalurgia" a menor variância explicada com 85,09\% e 83,36\% em 2004 e 2005, respectivamente. Constatou-se uma diferença no número de fatores a serem extraídos; o setor de "Veículos e Peças" apresentou o menor número, apenas 3 em 2005. Em alguns segmentos, houve a necessidade de se extrair 5 fatores.

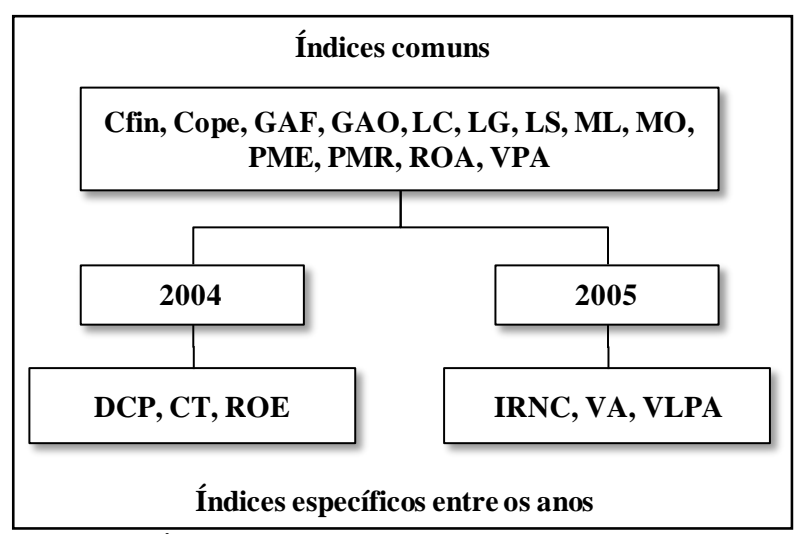

Figura 3: Índices do setor de indústria manufatureira

Fonte: Elaborado pelos autores

Dos 16 índices relevantes para o setor de Indústria Manufatureira em 2004, todos foram incluídos pelos menos uma vez entre os modelos dos segmentos. O segmento de "Siderurgia e Metalurgia" teve o menor número de índices relevantes em 2004, 9 no total, seguido pelos segmentos "Têxtil" com 13 índices, "Alimentos e Bebidas" e "Indústrias Químicas" com 14 índices e "Veículos e Peças" com 15 índices. Em 2005 dos 16 índices que entraram no modelo, o índice "Imobilização dos Recursos Não Correntes (IRNC)" não foi incluído como relevante em nenhum dos segmentos analisados, já os outros 15 índices apareceram em pelo menos um dos modelos. O segmento de "Veículos e Peças" apresentou o maior número de variáveis em 2005, 15 índices, sendo que os demais segmentos apresentaram 13 índices em seus modelos. A Figura 4 demonstra o número de índices selecionados para os modelos dos cinco segmentos estudados do setor de Indústria Manufatureira.

\begin{tabular}{|c|c|c|c|c|}
\hline \multicolumn{5}{|c|}{19 ÍNDICES RELEVANTES } \\
\hline $\begin{array}{l}\text { SIDERURGIA E } \\
\text { METALURGIA }\end{array}$ & $\begin{array}{l}\text { ALIMENTOS E } \\
\text { BEBIDAS }\end{array}$ & QUíMICA & TÊXTIL & VEÍCULOS E PEÇAS \\
\hline $\begin{array}{c}\text { ÁNALISE } \\
\text { FATORIAL }\end{array}$ & $\begin{array}{c}\text { ÁNALISE } \\
\text { FATORIAL }\end{array}$ & $\begin{array}{c}\text { ÁNALISE } \\
\text { FATORIAL }\end{array}$ & $\begin{array}{r}\text { ÁNALISE } \\
\text { FATORIAL }\end{array}$ & $\begin{array}{c}\text { ÁNALISE } \\
\text { FATORIAL }\end{array}$ \\
\hline 15 ÍNDICES & 16 ÍNDICES & 18 ÍNDICES & 16 ÍNDICES & 18 ÍNDICES \\
\hline
\end{tabular}

Figura 4: Número de índices selecionados para os segmentos do setor de indústria manufatureira Fonte: Elaborado pelos autores

Optou-se nesta pesquisa por considerar como relevantes os índices que foram incluídos no modelo, independentemente do ano; isto é, se um determinado índice foi 
relevante em um dos anos selecionados, ele foi utilizado. Esta metodologia foi adotada a fim de reduzir a sazonalidade e a variação que podem existir nos índices e no resultados das empresas com ações comercializadas na BOVESPA.

Na Tabela 8 são demonstrados os índices dos setores considerados relevantes para monitoramento dos gestores do setor de Indústria Manufatureira e os cinco segmentos estudados. A Tabela 8 permite ainda, observar que alguns índices relacionam-se com os cinco segmentos estudados, o que sugere que existem variáveis que podem ser denominadas como comuns.

Entre os segmentos, doze índices são semelhantes, destacando-se os índices de "Liquidez", "Ciclo Operacional”, "Margem Operacional”, "Margem Liquida”, "Prazo Médio de Estocagem", "Prazo Médio de Recebimento", “Alavancagem Financeira”, "Rentabilidade do Ativo", "Valor Do Lucro Por Ação", "Vendas Por Ação" e "Valor Patrimonial". Constatase, portanto, que esses indicadores são relevantes para monitoramento dos gestores do setor de Indústrias Manufatureiras e seus segmentos.

A análise fatorial identificou que os segmentos apresentaram indicadores específicos. O modelo considerou o índice "Grau de Alavancagem Operacional (GAO)" como importante para as Indústrias Químicas, Têxteis e de Veículos e Peças. A "Participação de Capital de Terceiros (CT)" é relevante para as empresas de Siderurgia e Metalurgia e Química. Os indicadores "Rentabilidade do Patrimônio Líquido (ROE)" e "Percentual da Dívidas de Curto Prazo sobre o Endividamento Geral (DCP)" foram incluídos nos modelos dos segmentos de Alimentos e Bebidas, Química, Têxtil e Veículos e Peças. A Figura 5 demonstra os índices comuns e específicos selecionados para os modelos dos segmentos manufatureiros estudados.

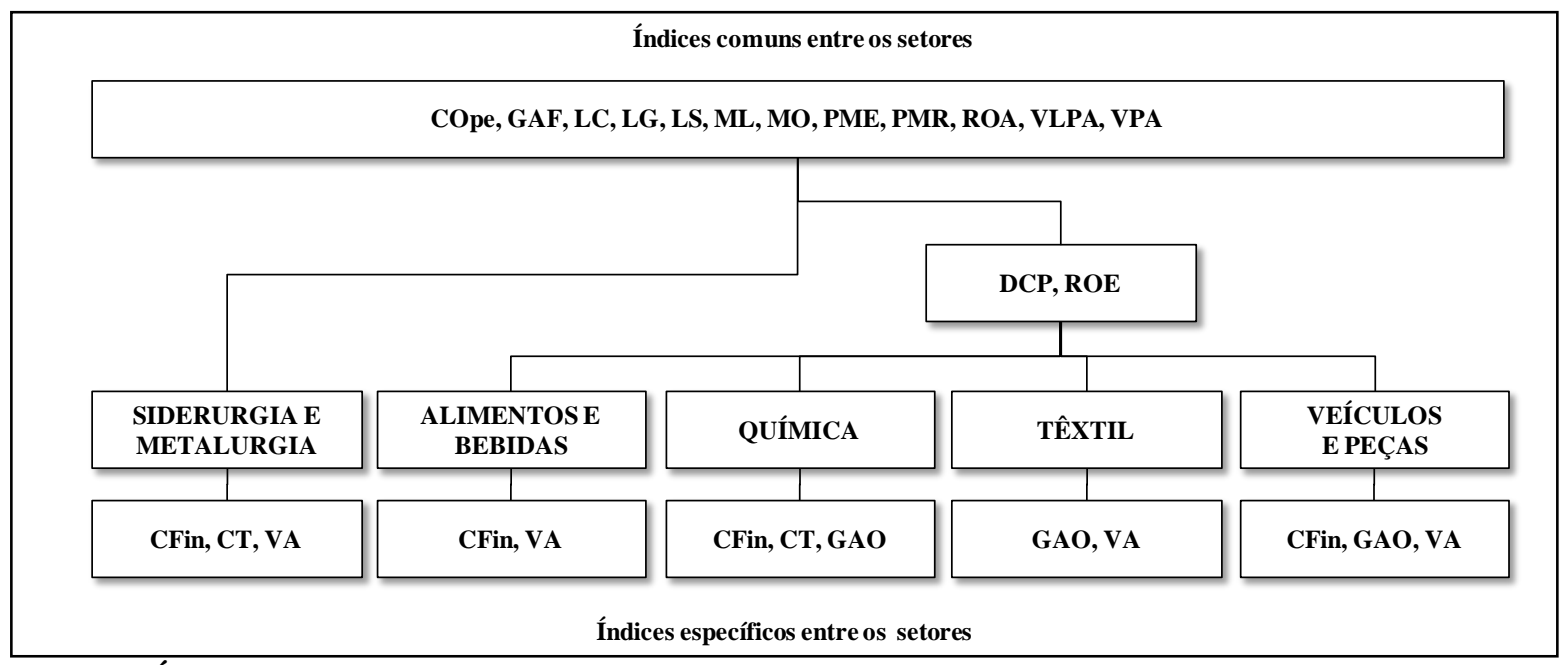

Figura 5: Índices selecionados por segmentos do setor de indústria manufatureira Fonte: Elaborado pelos autores 
Mesmo considerando os indicadores específicos, não há divergências significativas entre as características de mensuração dos índices que são relevantes para monitoramento pelos gestores dos cinco segmentos do setor de Indústria Manufatureira estudados.

Tabela 8 - Índices relevantes para o setor de indústria manufatureira e os seus segmentos estudados

\begin{tabular}{|c|c|c|c|c|c|c|}
\hline $\begin{array}{l}\text { Característica de } \\
\text { Mensuração }\end{array}$ & $\begin{array}{c}\text { Indústria } \\
\text { Manufatureira }\end{array}$ & $\begin{array}{l}\text { Siderurgia e } \\
\text { Metalurgia }\end{array}$ & $\begin{array}{l}\text { Alimentos e } \\
\text { Bebidas }\end{array}$ & Química & Têxtil & $\begin{array}{l}\text { Veículos e } \\
\text { Peças }\end{array}$ \\
\hline \multirow{2}{*}{$\begin{array}{l}\text { Índices de } \\
\text { Alavancagem }\end{array}$} & \multirow{2}{*}{$\begin{array}{l}\text { GAF } \\
\text { GAO }\end{array}$} & GAF & GAF & \multirow{2}{*}{$\begin{array}{l}\text { GAF } \\
\text { GAO }\end{array}$} & GAF & \multirow{2}{*}{$\begin{array}{l}\text { GAF } \\
\text { GAO }\end{array}$} \\
\hline & & & & & GAO & \\
\hline \multirow{4}{*}{$\begin{array}{l}\text { Índices de Ciclo } \\
\text { Operacional }\end{array}$} & CFin & CFin & CFin & \multirow{4}{*}{$\begin{array}{l}\text { CFin } \\
\text { COpe } \\
\text { PME } \\
\text { PMR }\end{array}$} & & CFin \\
\hline & COpe & COpe & Cope & & COpe & Cope \\
\hline & PME & PME & PME & & PME & PME \\
\hline & PMR & PMR & PMR & & PMR & PMR \\
\hline \multirow{3}{*}{$\begin{array}{l}\text { Índices de } \\
\text { Desempenho } \\
\text { Econômico }\end{array}$} & $\mathrm{VA}$ & $\mathrm{VA}$ & VA & \multirow{3}{*}{$\begin{array}{l}\text { VA } \\
\text { VLPA } \\
\text { VPA }\end{array}$} & VA & \multirow{3}{*}{$\begin{array}{c}\text { VA } \\
\text { VLPA } \\
\text { VPA }\end{array}$} \\
\hline & VLPA & VLPA & VLPA & & VLPA & \\
\hline & VPA & VPA & VPA & & VPA & \\
\hline \multirow{3}{*}{$\begin{array}{l}\text { Índices de Estrutura } \\
\text { de Capital }\end{array}$} & $\mathrm{CT}$ & $\mathrm{CT}$ & & \multirow{3}{*}{$\begin{array}{c}\mathrm{CT} \\
\mathrm{DCP}\end{array}$} & & \multirow{3}{*}{$\begin{array}{c}\mathrm{CT} \\
\mathrm{DCP}\end{array}$} \\
\hline & DCP & & $\mathrm{DCP}$ & & $\mathrm{DCP}$ & \\
\hline & IRNC & & & & & \\
\hline \multirow{3}{*}{ Índices de Liquidez } & $\mathrm{LC}$ & $\mathrm{LC}$ & $\mathrm{LC}$ & $\mathrm{LC}$ & LC & $\mathrm{LC}$ \\
\hline & LG & LG & LG & LG & LG & LG \\
\hline & LS & LS & LS & LS & LS & LS \\
\hline \multirow{4}{*}{$\begin{array}{l}\text { Índices de } \\
\text { Rentabilidade }\end{array}$} & ML & ML & ML & ML & ML & $\mathrm{ML}$ \\
\hline & MO & MO & MO & MO & MO & MO \\
\hline & ROA & ROA & ROA & ROA & ROA & ROA \\
\hline & ROE & & ROE & $\mathrm{ROE}$ & ROE & ROE \\
\hline
\end{tabular}

Fonte: Elaborado pelos autores

É importante ressaltar, que as Indústrias Manufatureiras produzem em grande escala e de forma bastante mecanizada e que se tratam, normalmente, de grandes empresas com alto valor de ativos e alto grau de endividamento. Podem, portanto, ser direcionadas para uma eficiente gestão de custos e de processo de distribuição. Diante disto, não foi possível identificar grandes divergências entre as características de mensuração dos índices nos cinco segmentos manufatureiros estudados.

Portanto, para os segmentos: "Siderurgia e Metalurgia"; "Alimentos e Bebidas"; "Química", "Têxtil" e "Veículos e Peças", os tomadores de decisão devem monitorar e gerenciar os índices extraídos para o setor de Indústria Manufatureira, pois, segundo a análise fatorial, esses índices fornecem uma visão adequada da situação de "rentabilidade", "ciclo operacional", "liquidez", "alavancagem", “desempenho econômico" e "estrutura de capital" dessas empresas. 


\section{RESULTADOS DA PESQUISA}

Inicialmente, após a aplicação da técnica de análise fatorial, foram identificados os índices relevantes para o conjunto total das empresas que possuem ações comercializadas na BOVESPA. Dos 24 indicadores econômico-financeiros selecionados, 21 foram considerados relevantes para o monitoramento dos gestores.

Posteriormente, uma segunda análise fatorial foi realizada, exclusivamente para o setor de Indústrias Manufatureiras, a qual permitiu identificar que destes 21 índices, 19 são relevantes para este setor e estão dispostos em sete fatores com poder de explicação de $77 \%$ da variabilidade dos dados. Os fatores identificados podem ser denominados como "ciclo operacional", "liquidez", “desempenho econômico", "rentabilidade", "alavancagem" e "estrutura de capital".

Por fim, uma terceira análise fatorial foi realizada, voltada agora para os cinco segmentos do setor manufatureiro estudados, e esta revelou os indicadores específicos que devem ser monitorados pelas empresas destes segmentos. Constatou-se ainda, que não há uma grande divergência nas características de mensuração dos indicadores relevantes de cada segmento com relação aos extraídos para o setor manufatureiro. Isso se deve ao fato destas empresas produzem em grande escala e de forma bastante mecanizada e a possuírem um valor elevado de ativos, bem como alto grau de endividamento. A gestão de custos e dos processos de distribuição deve merecer especial atenção desse setor. Assim, para estes segmentos destacam-se os índices de "liquidez", "ciclo operacional", "margem operacional", "prazo médio de estocagem", "prazo médio de recebimento", "alavancagem financeira", "rentabilidade do ativo", "valor do lucro por ação", "vendas por ação" e "valor patrimonial", como os principais a serem monitorados pelos tomadores de decisão.

Os resultados obtidos por meio da análise fatorial mostraram-se consistentes em identificar os índices relevantes e em fornecer um agrupamento de forma a potencializar as informações que são extraídas da análise tradicional das demonstrações financeiras, contribuindo assim para a diminuição da subjetividade dos analistas no processo de avaliação das empresas do setor de Indústria Manufatureira. Os resultados obtidos sugerem ainda, que a análise fatorial pode ser uma aliada importante para a tomada de decisões empresariais.

\section{REFER̂̂ENIAS}

ASSAF NETO, A. Estrutura e Análise de Balanços: um enforque econômico-financeiro. 8. ed. São Paulo: Atlas, 2008. 
BODIE, Z.; MERTON, R. C. Finanças. Trad. James Sudelland Cook. Porto Alegre: Bookman, 1999. (Tradução de: Finance. 1998).

BORSCHIVER, S.; WONGTSCHOWKI, P.; ANTUNES, A. A classificação industrial e sua importância na análise setorial. Revista Ciência da Informação, Brasília, v. 33, n. 1, p.9-21, jan./abril. 2004.

BRIGHAM, E. F.; GAPENSKI, L. C.; EHRHARDT, M. C. Administração financeira: teoria e prática. Trad. Alexandre Loureiro Guimarães Alcântara e José Nicolas Albuja Salazar. São Paulo: Atlas, 2001. (Tradução de: Financial management: theory and practice. 9 ed. 1999).

CORRAR, L. J.; PAULO, E.; DIAS FILHO, J. M. Análise Multivariada: para os cursos de Administração, Ciências Contábeis e Economia. São Paulo: Atlas, 2007.

GITMAN, L. J. Princípios de administração financeira. Trad. Jean Jacques Salim e João Carlos Douat. 7 ed. São Paulo: Harbra, 1997. (Tradução de: Principles of Managerial Finance. 7 ed. 1997).

HAIR, J. F. Jr. et al. Análise multivariada de dados. 6. ed. Porto Alegre: Bookman, 2009.

KASSAI, S. Utilização da Análise por Envoltória de Dados (DEA) na Análise de Demonstrações Contábeis. Tese (Doutorado em Contabilidade e Controladoria) - Faculdade de Economia, Administração e Contabilidade, Universidade de São Paulo, São Paulo, 2002.

MATARAZZO, D. C. Análise financeira de balanços: abordagem básica e gerencial. 5. ed. São Paulo: Atlas, 1998.

MINGOTI, S. A. Análise de dados através de métodos de estatística multivariada: uma abordagem aplicada. Belo Horizonte: UFMG, 2007.

ROSS, S. A.; WESTERFIELD, R. W.; JAFE, J. F. Administração financeira: corporate finance. Trad. Antonio Zoratto Sanvicente. São Paulo: Atlas, 2002. (Tradução de: Coportate finance. 5 ed. 1999)

SILVA, J. P. Análise financeira das empresas. 9. ed. São Paulo: Atlas, 2008. 